\title{
Epidemiology of perforated colonic diverticular disease
}

\author{
C R Morris, I M Harvey, W S L Stebbings, C T M Speakman, H J Kennedy, A R Hart
}

Postgrad Med J 2002;78:654-659

Perforated colonic diverticular disease results in considerable mortality and morbidity. This review appraises existing evidence on the epidemiology and mechanisms of perforation, highlights areas of further study, and suggests an epidemiological approach towards preventing the condition. Computerised searches were used to identify published articles relating to the epidemiology, pathophysiology, and clinical features of perforated colonic diverticular disease. Several drug and dietary exposures have potential biological mechanisms for causing perforation. Of these only non-steroidal anti-inflammatory drugs have been consistently identified as risk factors in aetiological studies. The causes of perforated colonic diverticular disease remain largely unknown. Further aetiological studies, looking specifically at perforation, are required to investigate whether cause-effect relationships exist for both drug and dietary exposures. The identification of risk factors for perforation would allow primary public health prevention, secondary risk factor modification, and early prophylactic surgery to be aimed at people at high risk.

See end of article for authors' affiliations

Correspondence to: Mr C R Morris, School of Medicine, Health Policy and Practice, Elizabeth Fry Building, University of East Anglia, Norwich NR4 7TJ,

UK; christopher.morris@ vea.ac.uk

Submitted 25 April 2002 Accepted 22 July 2002
D iverticular disease was first described in a medical textbook in 1920. ${ }^{1}$ Before this time, colonic diverticula were thought of mainly as an anatomical curiosity, although some observers had described the associated complications of perisigmoiditis, peritonitis, and fistula. ${ }^{2}$ Over the course of the 20th century, the prevalence of diverticular disease in Western industrialised countries increased. ${ }^{3}$ This was partly through a true increase in incidence, but also because of improved awareness and detection of the condition. In 1975 the prevalence of diverticulosis was estimated to be $5 \%$ by the age of 40 years, rising to $65 \%$ at 80 years $^{4}$ but no recent measures exist. However, diverticular disease is now an important condition in terms of healthcare utilisation with a recent report showing that it is one of the five most costly gastrointestinal disorders affecting the US population.'

While most people with diverticular disease remain asymptomatic, between $10 \%$ and 25\% develop symptoms, and of these $15 \%$ will develop significant complications. ${ }^{6}$ Complications can arise from perforation of a diverticulum either at a microscopic or macroscopic level (fig 1). ${ }^{7}$ The clinical manifestation of this event will depend on a number of factors, including the size of the perforation, the level of extracolonic contamination, and the body's ability to contain this contamination. The clinical features of perforation range from peridiverticulitis and small pericolic abscesses to large intra-abdominal or pelvic abscesses and purulent or faecal peritonitis. Rarely, patients with diverticular disease may also develop an associated segmental colitis, although it is unclear whether this is related to perforation. $^{8}$

The importance of perforated diverticular disease lies in the significant mortality associated with the severe manifestations of the condition. Most large case series show an overall mortality for patients requiring operative intervention of between $12 \%$ and $36 \%$. $^{9-15}$ In addition, there is considerable morbidity with many patients requiring intensive or high dependency care, formation of a stoma, and prolonged hospital stays. Those patients left with a stoma face a second and often difficult operation to restore intestinal continuity. Perforation, therefore, has serious implications for patients as well as consuming many healthcare resources.

The mortality rates from perforation appear to have remained unchanged over the last two decades, despite improvements in antibiotic therapy, intensive care, and surgical techniques. ${ }^{16}$ This may reflect the current lack of knowledge of the causes of this condition and strategies to prevent it. The aims of this review are to examine our present understanding of the epidemiology of colonic diverticular perforation, to highlight areas for further research, and to identify potential strategies for prevention.

\section{METHODS}

A computerised search of Medline (OVID), the Cochrane library, and the ISI Science Citation Index (ISI Web of Science) was performed. These databases were used to identify English language articles relating to the epidemiology, aetiology, pathophysiology, and clinical features of perforated diverticular disease for the period 1966 to December 2001. Because of the diverse terminology of the condition a broad range of subject headings were initially searched including "intestinal perforation", "diverticulitis", "colonic diverticulitis or diverticulosis", and "abdominal abscess". The search was focused by using the subheadings "epidemiology", "aetiology/ etiology", "pathology", "physiopathology", "complications", "prevention \& control". In addition, the terms "perforated diverticular disease", "perforated diverticulitis", "colonic perforation", and "colonic diverticulitis" were searched as keywords or words in the title. The bibliographies of all retrieved articles were reviewed. Major surgical and colorectal textbooks published in the last 


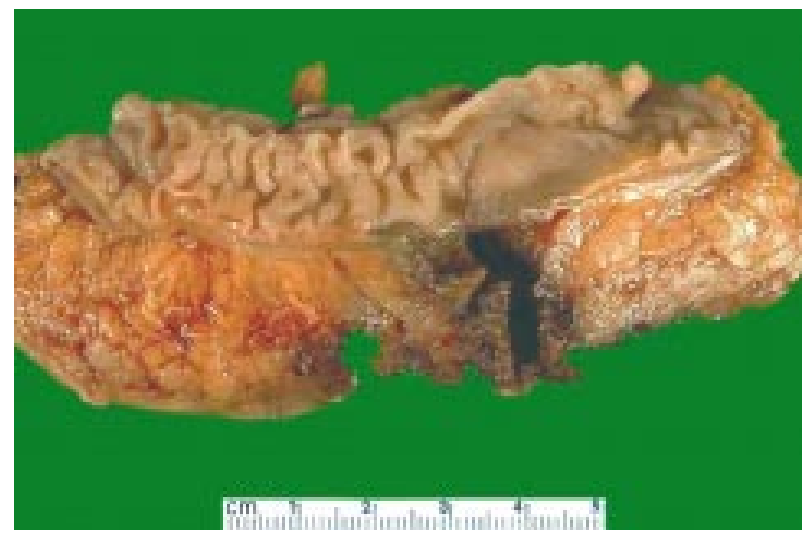

Figure 1 Opened section of sigmoid colon, showing macroscopic perforation of diverticulum. (Published with kind permission from Edward C Klatt MD, Department of Pathology, University of Utah, Salt Lake City, USA.)

Table 1 Severity grading of acute diverticulitis (Hinchey et $a^{19}{ }^{19}$ )

Stage 1 Diverticulitis with pericolic abscess

Stage 2 Diverticulitis with pelvic abscess or localised abscess

Stage 3 Diverticulitis with purulent peritonitis

Stage 4 Diverticulitis with faecal peritonitis

five years were also reviewed to identify additional references. Identified incidence, cross sectional, case-control, and cohort studies were cited. No randomised controlled clinical trials relating to the aetiology or prevention of perforated diverticular disease were found. Data on the clinical aspects and mortality of perforated diverticular disease were obtained, where possible, from large studies with greater than 100 cases.

\section{BIOLOGICAL MECHANISMS}

An understanding of the biological mechanisms of a disease is important in formulating hypotheses and, if risk factors are identified, in supporting a causal relationship. The pathogenesis of diverticular perforation remains speculative but the initial event is thought to involve an excessive rise in intradiverticular pressure either by blockage of the diverticular neck with faecal material or alternatively by exaggerated colonic segmentation. ${ }^{17}{ }^{18}$ This pressure increase leads to focal necrosis and perforation within the thin walled diverticulum allowing local bacterial proliferation in the surrounding serosa, pericolic fat, and mesentery. If this progresses, a collection of pus may form and in some cases become walled off by pericolic fat, to form a small pericolic abscess. If the collection enlarges it may involve loops of small bowel, omentum or the pelvic peritoneum forming a localised abscess. If the pus is not contained, contamination of the abdominal cavity occurs producing purulent peritonitis. Finally if the initial perforation is large, faecal peritonitis may occur rapidly without associated diverticular inflammation. ${ }^{18}$ Based on this process of progressive extracolonic sepsis, Hinchey et al have suggested a four stage classification of perforation (table 1 ). ${ }^{19}$

Patients with diverticular disease can generate markedly raised intracolonic pressures, ${ }^{20}{ }^{21}$ and the fact that nearly all diverticular perforations occur in the sigmoid colon, where the pressures are highest, is suggestive evidence that these changes are important. ${ }^{3}$ However, they are unlikely to be the only important factor as it has been shown that diverticula are capable, in normal conditions, of expanding greatly in response to large pressure increases. ${ }^{21}$ The properties of the colonic wall are also likely to be relevant in determining whether a perforation occurs. ${ }^{22}$ Diverticula lack the normal smooth muscle layers of the colon and consist predominantly of mucosa. The mucosa, therefore, acts as the main barrier to colonic content and supports a complex biochemical and bacterial environment under the control of both chemical and neurological stimuli. ${ }^{22-24}$ This environment is susceptible to alteration by exogenous factors leading to a breech of the mucosal defence and allowing rapid extracolonic passage of bacteria through the thin diverticular wall. In investigating the aetiology of colonic diverticular perforation, risk factors that produce impairment of the mucosal barrier as well as raised intracolonic pressures should be sought. Examples of potential risk factors are summarised in table 2 .

\section{EPIDEMIOLOGY OF PERFORATED DIVERTICULAR DISEASE}

\section{Descriptive studies}

An understanding of the frequency of a disease in varying populations is not only important for determining the resources for treating that condition, but can provide hypotheses for causation. The incidence rate is the most useful frequency measure for this purpose as unlike prevalence it is not influenced by duration of illness. Variations in the incidence of a disease between populations or specific groups often provide the first clues as to the cause of the condition.

One of the first studies to measure the frequency of the general, inflammatory complications of diverticular disease compared the incidence of diverticulitis in major teaching hospitals in Fiji, Singapore, Nigeria, and Scotland. ${ }^{47}$ The annual incidence in Scotland was estimated to be 12.9 cases per 100000 . This was 60 times greater than in the native populations of the other countries, reflecting the underlying prevalence of diverticular disease. Only one recent population based study has measured the incidence of diverticular perforation. This study measured the frequency of abscess and peritonitis secondary to diverticular perforation in Norfolk, UK. ${ }^{48}$ The incidence of perforation in this study was 4.0 cases per 100000 population per year and an estimated 2000 cases per year were calculated to occur in the UK. The study confirmed the expected finding of a higher incidence with increasing age but also showed the age adjusted incidence was higher in males (5.1/100 000/year in males versus 3.6/100 000/ year in females). This gender difference is supported by work from case series but only in younger age groups. In a series of 366 patients from Finland admitted with diverticulitis, there was a predominance of males in the under 50 year age group whereas the opposite was true in older age groups. ${ }^{49}$ This finding was consistent even after allowing for the baseline population. Other case series have shown a similar predominance of male patients in younger age groups. ${ }^{50}{ }^{51}$

Descriptive studies can also help to generate aetiological hypotheses in the initial stages of investigating a disease. In perforated diverticular disease, several small case series have implicated non-steroidal anti-inflammatory drugs (NSAIDs) as a possible aetiological factor. ${ }^{52-55}$ This has been supported by a larger case series that found $29 \%$ of cases of perforation were using NSAIDs. ${ }^{48}$ These drugs have a plausible mechanism of action in perforation in that they inhibit the cyclo-oxygenase enzyme and reduce prostaglandin synthesis in the gut. Prostaglandins are important for maintaining an effective colonic mucosal barrier as they stimulate secretion of mucin and bicarbonate and increase mucosal blood flow. ${ }^{56}$ In addition NSAIDs may cause topical mucosal damage, denuding surface epithelial cells and increasing colonic permeability. ${ }^{57}$ This may lead to ulceration and the passage of bacteria and toxins through the mucosa.

Case series of perforation have similarly found other drugs to be commonly used. One such study found that 11 of 49 patients $(22 \%)$ with perforation were taking steroids and that those on steroids had more severe inflammatory 
Table 2 Potential risk factors in diverticular perforation classified by biological mechanisms of action

\begin{tabular}{|c|c|c|}
\hline Mecahnism of action & Pathway & Risk factors \\
\hline $\begin{array}{l}\text { Raised intracolonic } \\
\text { pressure }\end{array}$ & $\begin{array}{l}\text { Altered autonomic activity } \\
\text { Opioid receptors } \\
\text { Reduced mechanical stretching of } \\
\text { colon }\end{array}$ & $\begin{array}{l}\text { Decreased physical exercise } 2526 \\
\text { Prostigmine/neostigmine }{ }^{2728} \\
\text { Opioid drugs } \\
\text { Fibre deficiency } 2931\end{array}$ \\
\hline Impaired mucosal barrier & $\begin{array}{l}\text { Altered microbial colonisation } \\
\text { Altered mucin secretion } \\
\text { Damaged epithelial cells } \\
\text { Decreased immune response }\end{array}$ & $\begin{array}{l}\text { Antibiotics } s^{3435} \\
\text { Fibre deficiency }^{36} \\
\text { NSAID }^{37-39} \\
\text { Fibre deficiency } \\
\text { NSAlD }^{40-42} \\
\text { Red meat }^{43} 4 \\
\text { Corticosteroids and other }^{44} \\
\text { immunosuppressants }^{45} \\
\text { Advanced age }^{46}\end{array}$ \\
\hline
\end{tabular}

Table 3 Evidence supporting association between NSAID use and complicated diverticular disease

\begin{tabular}{|c|c|c|c|c|}
\hline Study & Study design & Cases & Controls & $\begin{array}{l}\text { Relative risk/odds } \\
\text { ratio and } 95 \% \mathrm{CI} \text { for } \\
\text { NSAID use }\end{array}$ \\
\hline \multirow[t]{2}{*}{ Wilson et $a^{133}$} & \multirow[t]{2}{*}{ Case-control } & \multirow{2}{*}{$\begin{array}{l}92 \text { patients with complicated diverticular } \\
\text { disease. Inflammatory and bleeding } \\
\text { complications }\end{array}$} & 92 Community based & $11.2(7.1$ to 17.5$)$ \\
\hline & & & 306 Colorectal cancer patients & $6.6(3.6$ to 12.0$)$ \\
\hline Corder et a ${ }^{64}$ & Case-control & $\begin{array}{l}115 \text { patients with diverticular } \\
\text { disease/extracolonic sepsis }\end{array}$ & $\begin{array}{l}77 \text { patients with diverticular disease } \\
\text { and no extracolonic sepsis }\end{array}$ & 4.9 (1.6 to 14.8$)$ \\
\hline Langman et $a{ }^{155}$ & Case-control & $\begin{array}{l}107 \text { patients with small or large bowel } \\
\text { perforation }\end{array}$ & $\begin{array}{l}107 \text { patients with uncomplicated } \\
\text { bowel disease }\end{array}$ & $2.6(1.6$ to 4.1$)$ \\
\hline Campbell et alob & Case-control & $\begin{array}{l}50 \text { patients with severe complications of } \\
\text { diverticular disease }\end{array}$ & $\begin{array}{l}50 \text { emergency hospital admissions } \\
50 \text { patients with uncomplicated } \\
\text { diverticular disease }\end{array}$ & $\begin{array}{l}4.2(1.7 \text { to } 10.4) \\
3.7(1.5 \text { to } 9.0)\end{array}$ \\
\hline Aldoori et $a^{\beta 7}$ & $\begin{array}{l}\text { Cohort: } 35625 \text { male } \\
\text { health professionals }\end{array}$ & $\begin{array}{l}310 \text { self reported symptomatic } \\
\text { diverticular disease }\end{array}$ & & $2.2(1.3$ to 3.9$)$ \\
\hline
\end{tabular}

complications. ${ }^{58}$ Corticosteroids have powerful immunosuppressive actions as well as anti-inflammatory effects and it is likely that these drugs could impair a person's ability to contain a perforation in its early stages. Other studies have shown similar findings in patients receiving corticosteroids ${ }^{59-61}$ or other immunosuppressant drugs. ${ }^{62}$ Another case series has reported that a quarter of patients with perforation were taking opiate analgesics. ${ }^{48}$ Opiates have a plausible mechanism of action through their effects on raising intracolonic pressure and slowing intestinal transit. ${ }^{21}$ By slowing transit time they might prolong the exposure of the diverticular wall to potentially damaging intracolonic pathogens or agents.

\section{Analytical studies}

\section{Medication}

Descriptive studies have identified NSAIDs as a drug commonly used by patients with perforation and there is now consistent evidence from analytical studies that NSAIDs are associated with the complications of diverticular disease (table 3). Wilson et al showed that cases of complicated diverticular disease (bleeding and perforation) were significantly more likely to be taking NSAIDs than both an age and sex matched community based control group (34\% $v 4 \%$, $\mathrm{p}<0.001)$ and a group of colorectal cancer patients (34\% $\vee 7 \%$, $\mathrm{p}<0.001) .{ }^{63}$ Most of this association was attributable to the more severe complications of free perforation. A similar casecontrol study compared 50 patients with severe complications of diverticular disease with two control groups matched for sex and age. ${ }^{66}$ Again this study showed consistent and significant associations between NSAID use and complicated diverticular disease. In the case group, $48 \%$ were taking NSAIDs compared with $18 \%$ of the first control group (consisting of general emergency hospital admissions) and $20 \%$ of the second control group (consisting of patients with uncomplicated diverticular disease). However, this study included diverticular bleeding among the complications and difficulties arise in determining the risks for perforation alone.

Only one comparative study has looked specifically at diverticular perforation, ${ }^{64}$ comparing the use of medication in 115 cases of diverticular disease presenting with extracolonic sepsis (fistula, abscess, peritonitis) and 77 cases of diverticular disease without extracolonic sepsis (inflammatory mass, peridiverticulitis). In this study, both NSAIDs and corticosteroids were associated with the most severe clinical manifestations of perforation, namely peritonitis and abscess. Finally, a case-control study has found an association between NSAID use and perforations of the large and small bowel. ${ }^{65}$ Here 740 case records of gastrointestinal perforation or haemorrhage were analysed retrospectively to investigate drug use. Of the patients with perforation, $22 \%$ were taking NSAIDs compared with $10 \%$ of a control group consisting of patients with uncomplicated bowel disease $(\mathrm{p}<0.01)$. No association was detected with corticosteroid use.

No cohort studies have looked specifically at diverticular perforation, but a large investigation from the US has identified an association between NSAID use and symptomatic diverticular disease in men. ${ }^{67}$ This study followed a cohort of 35625 male health professionals for six years using questionnaires to look at use of NSAIDs and symptomatic diverticular disease. After adjusting for other potential confounding factors, men taking NSAIDs had a relative risk for the development of symptomatic diverticular disease of 2.2 (95\% confidence interval 1.3 to 3.9 ). 
However, in this study symptomatic diverticular disease was defined on the basis of self reported abdominal pain, bleeding, or change in bowel habit related to diverticular disease. It is unclear how many cases were attributable to perforation, bleeding, or simply mild symptoms.

The consistency of the evidence and the plausible biological mechanisms suggest that a causal relationship exists between NSAID use and diverticular complications. In particular, NSAIDs appear to be associated with the more severe complications of abscess and peritonitis. However, if these drugs are a true risk factor for perforation, they would account for less than $20 \%$ of cases ${ }^{48}$ Other risk factors must be important and could include drugs such as corticosteroids and opiate analgesics. Both have plausible mechanisms of action in perforation and observational evidence suggests they may be involved.

\section{Diet}

There are no studies that have examined whether associations exist specifically between diet and perforated colonic diverticular disease. However, variations in the incidence of perforation between countries with differing native diets, suggest that food components may be involved. ${ }^{47}$ A large US cohort study has shown that both a high red meat intake and low fibre intake (particularly a deficiency of fruit and vegetable fibre) increased the risk of symptomatic diverticular disease by threefold. ${ }^{68}$ This finding was supported by a case-control study from Greece, where red meat was shown to increase the risk of symptomatic diverticular disease while vegetables and brown bread were protective. ${ }^{69}$ As both these studies suggested that red meat and a deficiency of certain sources of dietary fibre may lead to the development of diverticular symptoms, it is also plausible that they could play a part in perforation. Fibre may protect against perforation by increasing stool weight and water content thus reducing colonic segmentation pressures and transit times. ${ }^{32}$ Furthermore, short chain fatty acids derived from the bacterial fermentation of fibre provide an important fuel source for colonic epithelial cells ${ }^{24} 70$ and may be important in maintaining an adequate colonic barrier. ${ }^{241}$ Red meat could predispose to perforation by the actions of its metabolites on colonic epithelial cells. Heterocyclic amines, products of cooked meat, have been associated with colonic mucosal cell apoptosis (programmed cell death $)^{43}$ while haem, the iron carrier in red meat, produces a highly cytotoxic factor in rat colons.$^{44}$ Further investigations are now required to specifically investigate the role of red meat and fibre intake in diverticular perforation.

\section{Smoking and alcohol}

Only two studies have looked at the relationship between smoking and diverticular disease and gave conflicting results. Of these, a large cohort study found no association between smoking and symptomatic diverticular disease ${ }^{72}$ while a casecontrol study identified smoking as a risk factor for complicated disease. ${ }^{73}$ In the case-control study, smoking increased the odds of diverticular complications, which included perforation, by threefold. ${ }^{73}$ The authors postulated that nicotine might predispose to inflammatory complications by reducing mucosal immunity in the colon. Smoking was highly correlated with alcohol intake, although the association between alcohol use and complications did not reach statistical significance.

Alcohol use has been investigated in a Danish study in which incidence rates of diverticulitis were compared between a cohort of alcoholics and the general population. ${ }^{74}$ It was found that the risk of diverticulitis was trebled in women alcoholics and doubled in male alcoholics. However, the validity of these findings is uncertain as there is a lack of clearly defined criteria for the diagnosis of diverticulitis and a failure to adjust for the potential confounding factors of smoking and diet. Further aetiological studies are now required to investigate smoking and alcohol habits specifically in diverticular perforation. Such studies should adjust for the potential confounding effects of diet.

\section{Conclusions}

This review has highlighted deficiencies in our understanding of both the incidence and aetiology of colonic diverticular perforation. Despite being a major source of morbidity and mortality, few studies have attempted to investigate the causes of perforation. Most identified studies have investigated the heterogenous categories of "complicated diverticular disease" or "symptomatic diverticular disease" instead of examining single well defined conditions such as perforation. This creates problems in interpreting associations and makes comparisons between studies difficult.

Descriptive studies show that, as expected, perforation is most frequent in industrialised countries with a high underlying prevalence of diverticulosis. The risk of perforation increases with advanced age and appears to be greater in men. Consistent evidence also suggests that NSAIDs are causally related to the severe complications of perforation and are probably involved in about a fifth of all cases. This review has highlighted other potential risk factors that may be involved. These include corticosteroids, opioid analgesics, smoking, alcohol use, excess red meat, and fibre deficiency all of which have plausible mechanisms for causing perforation but on which limited epidemiolgical data exists.

With a more complete understanding of the causes of diverticular perforation three levels of prevention could be adopted. Firstly, primary public health measures could be instigated through, for example, education about safe use of prescribed and over the counter medications. Secondly, patients identified with diverticular disease could be advised on modifying risk factors such as dietary components. Thirdly patients admitted to hospital with minor complications of diverticular disease could be stratified into risk groups according to their exposures. Based on the potential risk of perforation, an informed decision could be made on elective surgical resection at an early stage. With a lack of good quality aetiological data, the current scope for prevention of perforated diverticular disease is limited. The cautious use of NSAIDs in people with known diverticular disease may have some benefits in reducing the incidence of perforation, but as a single measure it is unlikely to have a large impact. Fibre supplementation remains the mainstay of medical management in symptomatic diverticular disease ${ }^{75}$ but this is based on inconsistent evidence ${ }^{76-78}$ and there is no evidence that fibre prevents complications such as perforation. ${ }^{77}$ Long term treatment with rifaximin, a poorly absorbed antibiotic, has been shown in a randomised clinical trial to improve symptoms in uncomplicated diverticular disease ${ }^{79}$ but such drugs have yet to be assessed in preventing perforation. The role of elective surgery in preventing complications is equally ambiguous with both the selection of patients and timing of surgery still debated. ${ }^{180}$ At present, there is simply not enough aetiological data to identify those who would benefit most from surgery.

This review suggests that there is a need for further good quality epidemiological research to specifically identify risk factors in colonic diverticular perforation. Such research would allow preventive measures to be directed at both the general population and high risk groups, benefiting patients and reducing the healthcare resources required to treat them.

\section{Authors' affiliations}

C R Morris, I M Harvey, A R Hart, School of Medicine, Health Policy and Practice, University of East Anglia, Norwich W S L Stebbings, C T M Speakman, Department of Surgery, Norfolk and Norwich University Hospital NHS Trust

H J Kennedy, Department of Gastroenterology, Norfolk and Norwich University Hospital NHS Trust 


\section{REFERENCES}

1 Telling WHM. Discussion on diverticulitis. Proc R Soc Med 1920:13:55-64

2 Schoetz DJ, Jr. Diverticular disease of the colon: a century-old problem. Dis Colon Rectum 1999;42:703-9.

3 Hughes LE. Postmortem survey of diverticular disease of the colon. I. Diverticulosis and diverticulitis. Gut 1969;10:336-44.

4 Painter NS, Burkitt DP. Diverticular disease of the colon, a 20th century problem. Clin Gastroenterol 1975;4:3-21.

5 American Gastroenterological Association. The burden of gastrointestinal diseases. Bethesda, MD: American Gastroenterological Association, 2001

6 Parks TG. Natural history of diverticular disease of the colon. Clin Gastroenterol 1975;4:53-69.

7 Wong WD, Wexner SD, Lowry A, et al. Practice parameters for the treatment of sigmoid diverticulitis - supporting documentation. The Standards Task Force. The American Society of Colon and Recta Surgeons. Dis Colon Rectum 2000:43:290-7.

8 Imperiali G, Meucci G, Alvisi C, et al. Segmental colitis associated with diverticula: a prospective study. Am J Gastroenterol 2000;95:1014-16.

9 Elliott TB, Yego S, Irvin TT. Five-year audit of the acute complications of diverticular disease. BrJ Surg 1997;84:535-9.

10 Tudor RG, Farmakis N, Keighley MR. National audit of complicated diverticular disease: analysis of index cases. Br J Surg 1994;81:730-2.

11 Finlay IG, Carter DC. A comparison of emergency resection and staged management in perforated diverticular disease. Dis Colon Rectum 1987; 30:929-33.

12 Nagorney DM, Adson MA, Pemberton JH. Sigmoid diverticulitis with perforation and generalized peritonitis. Dis Colon Rectum 1985;28:71-5.

13 Peoples JB, Vilk DR, Maguire JP, et al. Reassessment of primary resection of the perforated segment for severe colonic diverticulitis. Am J Surg 1990;159:291-3.

14 Zeitoun G, Laurent A, Rouffet F, et al. Multicentre, randomized clinical trial of primary versus secondary sigmoid resection in generalized peritonitis complicating sigmoid diverticulitis. Br J Surg

2000;87:1366-74

15 Kronborg O. Treatment of perforated sigmoid diverticulitis: a prospective randomized trial. Br J Surg 1993;80:505-7.

16 Keighley MRB, Williams NS. Left-sided colonic diverticular disease. In: Keighley MRB, Williams NS, eds. Surgery of the anus, rectum and colon. Philadelphia: WB Saunders, 1999: 1128-300.

17 Imbembo AL. Diverticular disease of the colon. In: Sabiston DCJ, Lyerly HK, eds. Textbook of surgery: the biological basis of modern surgical practice. Philadelphia: WB Saunders, 1997.

18 Ferzoco LB, Raptopoulos V, Silen W. Acute diverticulitis. N Engl J Med 1998:338: 1521-6.

19 Hinchey EJ, Schaal PG, Richards GK. Treatment of perforated diverticular disease of the colon. Adv Surg 1978;12:85-109.

20 Arfwidsson S, Kock NG, Lehmann L, et al. Intraluminal pressure in the sigmoid colon of normal subjects and patients with diverticular disease. Acta Chir Scand 1964;342:1-132.

21 Painter NS, Truelove SC. The intraluminal pressure patterns in diverticulosis of the colon. Part II: the effect of morphine. Gut 1964;5:207-13

22 Watters DA, Smith AN. Strength of the colon wall in diverticular disease. Br J Surg 1990;77:257-9.

23 Macfarlane GT, Macfarlane S. Human colonic microbiota: ecology, physiology and metabolic potential of intestinal bacteria. Scand J Gastroenterol Suppl 1997:222:3-9.

24 Edwards C. Physiology of the colorectal barrier. Advanced Drug Delivery Reviews 1996;28: 173-90.

25 Rao SS, Beaty J, Chamberlain $M$, et al. Effects of acute graded exercise on human colonic motility. Am J Physiol 1999;276:G1221-6.

26 Sarna SK. Physiology and pathophysiology of colonic motor activity (2). Dig Dis Sci 1991;36:998-1018.

27 Painter NS. The effect of neostigmine methyl sulphate on the human colon in health and in diverticulosis. Proc R Soc Med 1967;60:219-20.

28 Sasaki D, Munakata A, Saitoh Y, et al. Anti-spasmodic effect of prifinium bromide on the proximal and distal colon in patients with diverticular disease. Gastroenterol Jpn 1981;16:344-9.

29 Frantzides CT, Condon RE, Schulte WJ, et al. Effects of morphine on colonic myoelectric and motor activity in subhuman primates. Am J Physiol 1990;258:G247-52.

30 Frantzides CT, Cowles V, Salaymeh B, et al. Morphine effects on human colonic myoelectric activity in the postoperative period. Am J Surg 1992; 163:144-8.

31 Schang JC, Hemond M, Hebert $M$, et al. How does morphine work on colonic motility? An electromyographic study in the human left and sigmoid colon. Life Sci 1986;38:671-6.

32 Cummings $\mathbf{J H}$, Stephen AM. The role of dietary fibre in the human colon. Can Med Assoc J 1980;1 23:1 109-14.

33 Eastwood MA, Smith AN, Brydon WG, et al. Comparison of bran, spaghula, and lactulose on colon function in diverticular disease. Gut 1978;19:1144-7.

34 Edlund C, Nord CE. Effect on the human normal microflora of oral antibiotics for treatment of urinary tract infections. J Antimicrob Chemother 2000;46(suppl 1):41-8.

35 Cavallaro V, Catania V, Bonaccorso R, et al. Effect of a broad-spectrum cephalosporin on the oral and intestinal microflora in patients undergoing colorectal surgery. J Chemother 1992;4:82-7.
36 Gibson GR. Dietary modulation of the human gut microflora using prebiotics. Br J Nutr 1998:80:S209-12.

37 Levi S, Shaw-Smith C. Non-steroidal anti-inflammatory drugs: how do they damage the gut? Br J Rheumatol 1994;33:605-12.

38 Davies NM, Wallace JL. Nonsteroidal anti-inflammatory drug-induced gastrointestinal toxicity: new insights into an old problem. J Gastroenterol 1997:32: 127-33

39 Cryer B. NSAID gastrointestinal toxicity. Current Opinion in Gastroenterology 2000;16:495-502

40 Barcelo A, Claustre J, Moro F, et al. Mucin secretion is modulated by uminal factors in the isolated vascularly perfused rat colon. Gut 2000;46:218-224.

41 Scheppach W. Effects of short chain fatty acids on gut morphology and function. Gut 1994;35(1 suppl)S35-8.

42 Finnie IA, Dwarakanath AD, Taylor BA, et al. Colonic mucin synthesis is increased by sodium butyrate. Gut 1995;36:93-9.

43 Hirose $Y$, Sugie S, Yoshimi N, et al. Induction of apoptosis in colonic epithelium treated with 2-amino-1-methyl-6-phenylimidazo[4,5-b]pyridine (PhIP) and its modulation by a P4501A2 inducer, beta-naphthoflavone, in male F344 rats. Cancer Lett 1998;123:167-72.

44 Sesink AL, Termont DS, Kleibeuker JH, et al. Red meat and colon cancer: the cytotoxic and hyperproliferative effects of dietary heme. Cancer Res 1999:59:5704-9.

45 Routes J, Claman HN. Corticosteroids in inflammatory bowel disease. A review. J Clin Gastroenterol 1987;9:529-35.

46 Ginaldi L, De Martinis M, D'Ostilio A, et al. The immune system in the elderly: I. Specific humoral immunity. Immunol Res 1999;20:101-8.

47 Kyle J, Adesola AO, Tinckler LF, et al. Incidence of diverticulitis. Scand J Gastroenterol 1967:2:77-80.

48 Hart AR, Kennedy HJ, Stebbings WS, et al. How frequently do large bowel diverticula perforate? An incidence and cross-sectional study. Eur Gastroenterol Hepatol 2000;12:661-5

49 Makela J, Vuolio S, Kiviniemi H, et al. Natural history of diverticular disease: when to operate? Dis Colon Rectum 1998:41:1523-8.

50 Ambrosetti P, Robert JH, Witzig JA, et al. Acute left colonic diverticulitis in young patients. J Am Coll Surg 1994;179:156-60.

51 Schaver PR, Ramos R, Ghiatas AA, et al. Virulent diverticular disease in young obese men. Am J Surg 1992;164:443-6.

52 Schwartz HA. Lower gastrointestinal side effects of nonsteroidal antiinflammatory drugs. J Rheumatol 1981;8:952-4.

53 Sheers R, Williams WR. NSAIDs and gut damage. Lancet 1989;ii: 1154.

54 Day TK. Intestinal perforation associated with osmotic slow release indomethacin capsules. BMU 1983;287:1671-2.

55 Coutrot S, Roland D, Barbier J, et al. Acute perforation of colonic diverticula associated with short-term indomethacin. Lancet 1978;ii: 1055-6.

56 Davies NM. Toxicity of nonsteroidal anti-inflammatory drugs in the large intestine. Dis Colon Rectum 1995;38:1311-21.

57 Davies NM. Review article: non-steroidal anti-inflammatory drug-induced gastrointestinal permeability. Aliment Pharmacol Ther 1998;12:303-20.

58 Canter JW, Shorb PE Jr. Acute perforation of colonic diverticula associated with prolonged adrenocorticosteroid therapy. Am J Surg $1971 \cdot 121: 46-51$

59 Weiner HL, Rezai AR, Cooper PR. Sigmoid diverticular perforation in neurosurgical patients receiving high-dose corticosteroids. Neurosurgery 1993;33:40-43

60 Beaver TM, Fullerton DA, Zamora MR, et al. Colon perforation after lung transplantation. Ann Thorac Surg 1996;62:839-43.

61 Candelas G, Jover JA, Fernandez B, et al. Perforation of the sigmoid colon in a rheumatoid arthritis patient treated with methylprednisolone pulses. Scand J Rheumatol 1998;27:152-3.

62 Tyau ES, Prystowsky JB, Joehl RJ, et al. Acute diverticulitis. A complicated problem in the immunocompromised patient. Arch Surg $1991 ; 126: 855-8$

63 Wilson RG, Smith AN, Macintyre IM. Complications of diverticular disease and non-steroidal anti- inflammatory drugs: a prospective study. Br J Surg 1990;77: 1103-4.

64 Corder A. Steroids, non-steroidal anti-inflammatory drugs, and serious septic complications of diverticular disease. BM 1987;295:1238.

65 Langman MJ, Morgan L, Worrall A. Use of anti-inflammatory drugs by patients admitted with small or large bowel perforations and haemorrhage. BN 1985;290:347-9.

66 Campbell K, Steele RJ. Non-steroidal anti-inflammatory drugs and complicated diverticular disease: a case-control study. Br J Surg 1991;78:190-1.

67 Aldoori WH, Giovannucci EL, Rimm EB, et al. Use of acetaminophen and nonsteroidal anti-inflammatory drugs: a prospective study and the risk of symptomatic diverticular disease in men. Arch Fam Med $1998 ; 7: 255-60$

68 Aldoori WH, Giovannucci EL, Rimm EB, et al. A prospective study of diet and the risk of symptomatic diverticular disease in men. Am J Clin Nutr 1994;60:757-64.

69 Manousos O, Day NE, Tzonou A, et al. Diet and other factors in the aetiology of diverticulosis: an epidemiological study in Greece. Gut 1985;26:544-9

70 Anonymous. Dietary fibre: importance of function as well as amount [editorial]. Lancet 1992;340:1133-4.

71 Mariadason JM, Catto-Smith A, Gibson PR. Modulation of distal colonic epithelial barrier function by dietary fibre in normal rats. Gut 1999;44:394-9.

72 Aldoori WH, Giovannucci EL, Rimm EB, et al. A prospective study of alcohol, smoking, caffeine, and the risk of symptomatic diverticular disease in men. Ann Epidemiol 1995;5:221-8. 
73 Papagrigoriadis S, Macey L, Bourantas N, et al. Smoking may be associated with complications in diverticular disease. Br J Surg 1999;86:923-6

74 Tonnesen H, Engholm G, Moller H. Association between alcoholism and diverticulitis. Br J Surg 1999:86:1067-8.

75 Wong WD. Wexner SD, Lowry A, et al. Practice parameters for the treatment of sigmoid diverticulitis - supporting documentation. The Standards Task Force. The American Society of Colon and Rectal Surgeons. Dis Colon Rectum 2000;43:290-7.

76 Brodribb AJ. Treatment of symptomatic diverticular disease with a high-fibre diet. Lancet 1977;i:664-6.
77 Simpson J, Spiller R. Colonic diverticular disease. Clinical Evidence $2001 ; 6: 336-43$.

78 Ornstein MH, Littlewood ER, Baird IM, et al. Are fibre supplements really necessary in diverticular disease of the colon? [letter]. BM 1981;282:1629-30.

79 Papi C, Ciaco A, Koch M, et al. Efficacy of rifaximin in the treatment of symptomatic diverticular disease of the colon. A multicentre double-blind placebo-controlled trial. Aliment Pharmacol Ther 1995;9:33-9.

80 Hulten L, Haboubi NY, Schofield PF. Diverticular disease. Colorectal Disease 1999;1:128-36.

\section{$\mathrm{ECHO}$}

\section{New definition of MI lacks evidence base}

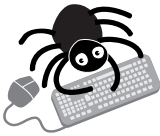

Please visit the Postgraduate Medical Journal website [www. postgradmedi com] for link to this full article.
The European Society of Cardiology (ESC) and American College of Cardiology (ACC) have proposed a new definition of MI, which differs substantially from the widely used WHO definition and hinges on increased troponin concentration as a marker for MI.

Now an editorial cautions against relying too much on this marker without knowing the value of troponins across the entire range of acute coronary disease. "There is little justification for adopting at face value the holistic approach suggested by the joint ESC/ACC document, at least not immediately." MI should continue to be diagnosed as before, until enough evidence becomes available from clinical trials, the editorial recommends.

Under the new definition, unstable angina as previously defined would become MI, with important consequences for epidemiology, patients, and resources. At a practical level troponin assays have not been tested for their robustness, their reproducibility over time is uncertain, and they need to be standardised. Also their cost effectiveness should be compared with that for standard assays for other biochemical markers such as creatine kinase.

Troponins have come to the fore in diagnosing MI because of new terminology for acute coronary syndromes, in which acute Q wave MI is added alongside non-Q wave MI and unstable angina, and management is based on ECG and biochemical markers-especially troponins-at presentation. Troponin concentration is currently used to identify non-ST segment MI from an atypical clinical picture with no acute ECG changes or unstable angina if acute ischaemia is present.

( Heart 2002;88:1-3. 